\title{
Evaluating The Efficiency Of Technology Transfer In The Processing Industries: An Empirical Approach Based On Data Envelopment Analysis DEA Of The Processing Industries In The Souss-Massa Region
}

\author{
Moulay Abdessadk El hamdania ${ }^{a}$ Abdelaziz Bendou ${ }^{b}$ \\ a'University IbnZohr, Agadir, Morocco. E-mail: eabdessadk@gmail.com \\ bUniversity IbnZohr, Agadir, Morocco. E-mail: a.bendou@uiz.ac.ma
}

Article History: Received: 11 January 2021; Accepted: 27 February 2021; Published online: 5 April 2021

\begin{abstract}
Technology transfer is a powerful growth factor in industrial value added in the processing industries. Of course, it is important to assess the efficiency of technology transfer in the processing industry by analysing its influencing factors and discussing strategies to improve technological innovation. However, it is still difficult to measure its direct impact on the improvement or creation of value added, and one of the most relevant indicators that could measure the real impact of technology transfer is efficiency. The efficiency of the modes of technology transfer will therefore be the comparative relationship between inputs and outputs in the technology transfer activities based. It is an indicator for measuring the profitability of technology investment in industrial transformation. In our study, we will try to integrate a mathematical tool that allows us to solve optimization problems using a program operating under different constraints imposed by a model. The usefulness of this model depends on the ability to implement it, by the managers of production lines who are called upon to implement $\mathrm{R} \& \mathrm{D}$, innovation or technology transfer projects. Based on panel data of processing industries that use one or more modes of technology transfer in the Souss-Massa region, this article will examine trends in the efficiency of technology transfer use, mainly as a result of technological progress and the promotion of technology transfer.
\end{abstract}

Keywords: Technology Transfer, Innovation, Data Envelopment Analysis.

\section{Introduction}

Technology is in the heart of processing industries. Technology transfer is assessed according to the degree of technological innovation available (Feichtinger, et al., 2014). Industries need to rely on technological innovation to improve labor productivity, which improves the efficiency of processing and the creation of value added.

Technological innovation is therefore an engine for growth in industrial value added in the processing industries. Of course, it is important to assess the efficiency of technology transfer in the processing industry by analyzing its influencing factors and discussing strategies to improve technological innovation. However, the main indicator that could measure the real impact of innovation and technology transfer is efficiency.

Based on panel data of processing industries that use one or more modes of technology transfer, this paper will examine trends in the efficiency of technology transfer use of processing industries in the Souss-Massa region, mainly due to technological progress and promotion of technology transfer. The efficiency of technology transfer modes is the comparative relationship between inputs and outputs in technology innovation activities based on technology transfer. It is an indicator for measuring the profitability of technological investment in industrial transformation.

This paper will analyze productivity within the processing industries of the Souss-Massa and will investigate the reason for the distinction between enterprises which have diverse levels of dominance of the Technology Transfer.

\section{Issue}

Technology transfer is a complex system with multiple issues and factors. The term "technology transfer" is broad and difficult to measure (Agrawal, 2001). The evaluation of the actual effect of technology transfer requires consideration of the Decision Making Unit (DMU) with multiple inputs and outputs.

Overall the technology transfer process comprises different phases and parts and its performance is measured by the value added income generated by universities and technology transfer institutions. Despite the fact that almost all universities conduct technology transfer activities, most technology transfer offices do not benefit from their marketing activities. However, the use of technology transfer revenues does not 
Evaluating The Efficiency Of Technology Transfer In The Processing Industries: An Empirical Approach Based On Data Envelopment Analysis DEA Of The Processing Industries In The SoussMassa Region

measure actual performance because they do not provide real results and are not based on the potential of the technology transfer resulting from university research (Vinig \& Lips, 2015).

The Global Innovation Index report uses a tool that measures 84 parameters to assess the "innovation index" by country (Wunsch-Vincent, 2018). The GII (average) and the innovation efficiency ratio is the final function based on the two main sub-indices, innovation input and innovation output. The innovation efficiency ratio is used to highlight those economies that have achieved more with fewer resources, as well as those that are lagging behind in terms of realizing their innovation potential. It is designed to assess the effectiveness of innovation systems and portfolios and can highlight in efficient innovators.

In the processing industries, project developers can compete fiercely for access to limited resources (capital, personnel, physical facilities, equipment, etc.). If this portfolio management is not formalized, it comes under pressure from interest groups. It is the open door to personality biases, individual preferences and emotions. In order to systematize the evaluation process, models have been designed (Jolly, 2013).

The literature review on technology transfer evaluation suggests models that cross-reference the prospects for productivity improvement with those for output; others focus more on theimportance of the technology and the competitive position of the firm. These are quite useful models according to (Vinig \& Lips, 2015). On the other hand, very little attention has been paid to the indicators that practitioners should use to evaluate their technological projects, particularly inthe processing industry.

In our study, we will try to integrate a mathematical tool that allows solving optimization problems thanks to a program running under different constraints imposed by a model. The usefulness of this model depends on the ability to implement it, by the managers of production lines who are called upon to implement R\&D, innovation or technology transfer projects.

\section{Choosing a Method}

The DEA method addresses the weaknesses of partial productivity ratios and the difficulties of applying traditional total productivity ratios (Halkos \& D, 2004).

The DEA is based on Shephard's concept of production technology (Shepherd, 2016) This concept makes it possible to represent the efficiency of the entities studied on the basis of the relationship that links all of the resources used as inputs to all of the services produced as outputs. The indicator thus calculated is the "technical inefficiency score".

Each company's efficiency score is calculated in relation to an efficiency frontier. The production lines that are located on the border have a score of 1 (or 100\%). Organizations that are located below the border have a score of less than 1 (or 100\%) and therefore have room to improve their performance. Note that no organization can be above the efficiency frontier because it is not possible to score above $100 \%$. Organizations on the border serve as peers to inefficient organizations. These peers are associated with observable best practices (Huguenin, 2013).

To understand the "mechanical" operation of the AED method, a simple practical case is developed in the diagram below Figure 1. It includes five companies operating with one input and one output. It should be remembered, however, that the DEA method can include multiple inputs and outputs.

The DEA frontier can be estimated according to two techniques: The first is input-oriented, it aims at optimizing or reducing as much as possible the consumption of inputs for a given level of outputs. The second is outputoriented, its objective is to maximize the outputs for a given level of inputs.

Two basic models are used in AED, each leading to the identification of a different efficiency frontier. The first model assumes that firms operate in a situation of constant returns to scale (constant returns to scale model -CRS-). It is appropriate when all organizations have reached their optimalsize.

The assumption of this model is ambitious. Because to operate at their optimal size, companies must operate in an environment of perfect competition. This model makes it possible to calculate an efficiency score called constant return to scale technical efficiency (CRSTE) (Huguenin, 2013).

The second model assumes that firms operate in a situation of variable returns to scale (variable returns to scale model -VRS-). It is appropriate when organizations do not operate at their optimal size. This assumption is 
preferred in cases of imperfect competition. The VRS model calculates an efficiency score called variable returns to scale technical efficiency (VRSTE).

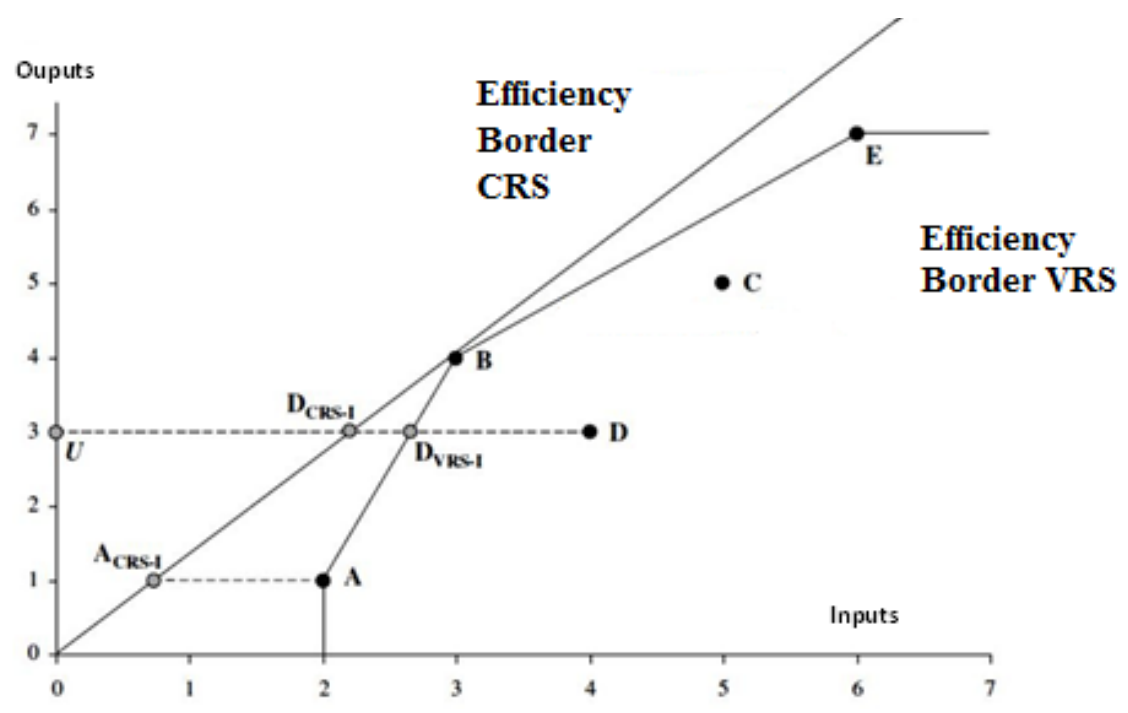

Figure 1. Efficiency Borders CRS and VRS

The Figure 1shows the CRS and VRS efficiency boundaries on the same graph. Company B is located on both boundaries at the same time. It is therefore CRS and VRS efficient.

Firms $\mathrm{A}$ and $\mathrm{E}$ are efficient assuming variable returns to scale but inefficient assuming constant returns to scale. They are on the VRS frontier but not on the CRS frontier. Finally, firms D and C are CRS and VRS inefficient. They are not on either boundary.

The observed difference between the CRS and VRS boundaries is explained by inefficiency of scale. Firms on the CRS border operate at the optimal size; those on the VRS border operate at the optimal size.

a non-optimal size, i.e. a size that does not allow them to minimize their average resource consumption. As an illustration, company A is VRS efficient. To become

As an efficient CRS, it must change its size (or the scale at which it operates).

Company A can achieve this by moving from point A to point ACRS-I. At this point, it becomes as productive as firm $\mathrm{B}$, which is the only efficient CRS.

Two companies (D and E) are not even located on the VRS border. These companies not only have a size problem; they are also poorly managed. For example, company D has to move to DVRS-I (located on the VRS boundary) to become an efficient VRS (i.e., to reverse its inefficiency due to poor management). Company D must make an additional movement from DVRS-I to DCRS-I (located on the CRS border) to become CRS efficient (i.e., to offset its inefficiency due to a significant problem). Consequently, CRS efficiency (also called total efficiency) is broken down into two parts: VRS efficiency (also called pure efficiency) and efficiency of scale. The following ratios represent these three types of efficiency applied to undertaking $\mathrm{D}$ (in the case of input orientation).

Table 1. Types of efficiency applied to the company D

\begin{tabular}{ccc}
$\begin{array}{c}\text { Technical efficiency of D under CRS } \\
\text { assumption (total efficiency) }\end{array}$ & $\begin{array}{c}\text { Technical efficiency of D under VRS } \\
\text { assumption (pure efficiency) }\end{array}$ & $\begin{array}{c}\text { Efficiency of } \\
\text { scale of D }\end{array}$ \\
\hline$T E_{C R S}=\frac{U D_{C R S-I}}{U D}$ & $T E_{V R S}=\frac{U D_{V R S-I}}{U D}$ & $E=\frac{U D_{C R S-I}}{U D_{V R S-I}}$ \\
\hline
\end{tabular}

\section{Implementation of the Method}

Our practical study deals with 48 firms in the Souss-Massa region that use at least one of the modes of technology transfer cited by the authors. (Hamdani \& Bendou, 2019) These include patents and licenses, subcontracting and technological services. Over a period of five years, companies produce an output, which in this case is the evolution of value added with the help of two inputs, namely investment in technology transfer and training of personnel in these new technologies. 
Evaluating The Efficiency Of Technology Transfer In The Processing Industries: An Empirical Approach Based On Data Envelopment Analysis DEA Of The Processing Industries In The SoussMassa Region

Figure 2. represents the first table of results of DEAP ${ }^{1}$ software and contains a summary of the efficiency analysis. The first column represents the identifiers of the 48 companies, identified by the numbers 1 to 48 . The second column contains the efficiency scores under the assumption of constant returns to scale (CRSTE), which also corresponds to total efficiency. This total efficiency is decomposed into a measure of pure efficiency (efficiency assuming variable returns to scale -VRSTE- in the third column) and a measure of efficiency of scale (SCALE in the fourth column). The last column indicates the type of returns to scale (RSI, RSD or a dash):

Companies associated with IRS Increasing returns to scale operate in a situation of increasing returns to scale (economies of scale). This situation occurs when the average consumption of resources decreases with an increase in output produced. An organisation in such a situation has not yet reached its optimal size. To improve its efficiency of scale, it must increase its output. In a situation of economies of scale, a variation in output production of $1 \%$ implies a variation in input consumption of less than $1 \%$. Thus, an increase in output production results in a reduction in the average consumption of resources;

Companies associated with DRS Decreasing returns to scale are in a situation of decreasing returns to scale (diseconomies of scale). This situation occurs when the average consumption of resources decreases with an increase in output produced. An organization in such a situation has not yet reached its optimal size. To improve its efficiency of scale, it must increase its output. In a situation of economies of scale, a variation in output production of $1 \%$ implies a variation in input consumption of less than $1 \%$. Thus, an increase in output production leads to a reduction in the average consumption of resources; size.

Associated companies with a dash move in a situation of constant returns to scale; they operate at their optimal

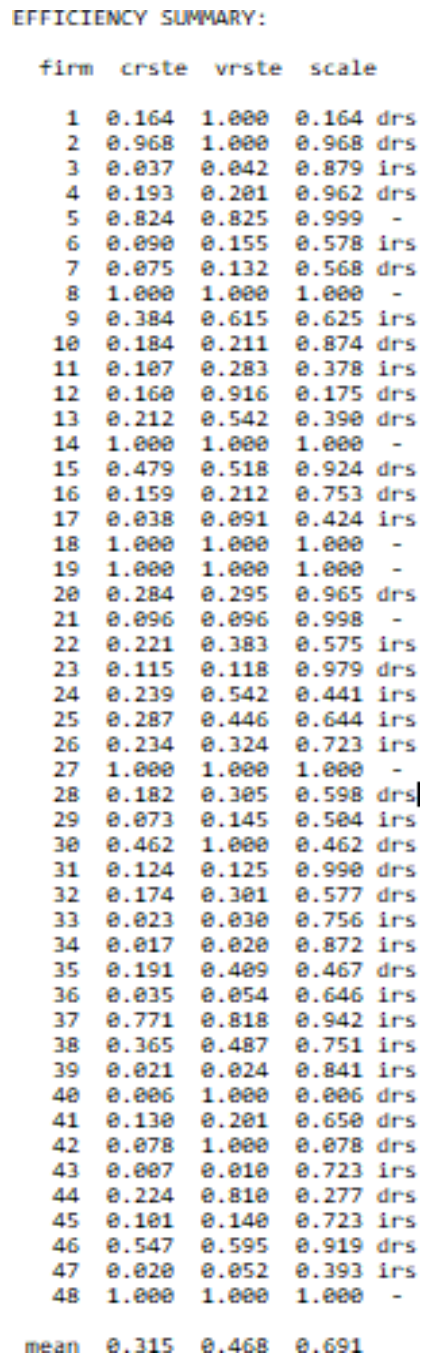

${ }^{1}$ A console program developed by Tim Coelli (Queensland University). 
Figure 2. Efficiency analysis results

On average, companies achieve the following efficiency scores:

- $\quad 31.5 \%$ for CRSTE; in total, companies can reduce all their inputs by $68.5 \%$ while having the same added value.

- $46.8 \%$ for VRSTE; better management of technology transfer makes it possible to reduce input consumption by $53.2 \%$ while training the same number of students.

- $\quad 69.1 \%$ for SCALE; by adjusting their size, companies can reduce their inputs by $30.9 \%$ while having the same added value.

The DEAP software provides a results file, all results are presented as a table of individual situations of each company. In order to identify the potential for improvement of the companies studied, the software refers to the pure technical efficiency score VRSTE, i.e. without taking into account the efficiency of scale.

The result tables contain the following information:

- $\quad$ The company number ("Results for firm");

- The technical efficiency score ("Technical efficiency"), which corresponds to VRSTE in the case of a VRS model (or to CRSTE in the case of CRS model); the scale efficiency score ("Scale efficiency") note that the OS appears only in the case of a VRS model;

The lines of the matrix represent the outputs and inputs of the model.

- the first column of the matrix recalls the original values of the variables -outputs and inputs- ("original value");

- The second column of the matrix contains the movements that inefficient organizations must make in order to be on the efficiency frontier ("radial movement");

- The third column of the matrix represents the additional movements that organizations on a segment of the axis-parallel boundary must make to become efficient ("slack movement");

- The fourth column of the matrix contains the values of the variables that enable organizations to be efficient. ("projected value"); these projected values take into account not only the radial movements but also the SLAKES MOVEMENTS;

- Finally, the peers are listed; each peer is identified by its number; a weight ("lambda weight") is associated with each pair; this weight represents the relative importance of the peer.

To illustrate, the individual results tables of a company (company number 7)

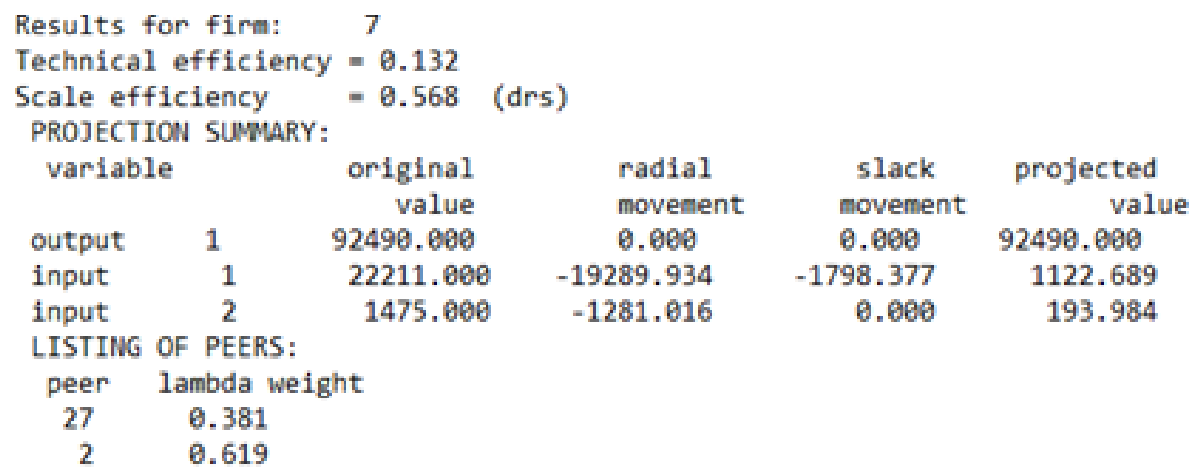

Figure 3. Individual company results

Company 7 (see Figure 3.Individual company results) has a pure efficiency of $13.2 \%$ and an efficiency of scale of $56.8 \%$. It operates in a situation of diminishing returns to scale (DRS). By improving the way in which technology transfer is managed, $86.8 \%(100-13.2)$ of the inputs can be saved. By adjusting the size of the enterprise, input consumption can be reduced by $43.2 \%$ (100 - 56.8).

The original values of the enterprise variables are recalled in the table: enterprise 1 improved its value added by 92490,000 MAD with an investment of 22211,000 MAD in the transfer of material technologies, and 1475,000 $\mathrm{MAD}$ in the training of personnel in these technologies. 
However, this enterprise could produce the same quantity of outputs with fewer inputs: 1122,689 MAD instead of 22211,000 in material technology transfer and 193,984 MAD instead of 1475,000 in training (see "projected value" column).

The case of input 1 is a little different because it presents a "slack movement": for the company to be efficient, this input must not only be reduced by (- 19289,934 MAD (column "radial movement"), but also by an additional 1798,377 MAD (column "slack movement"). In total, company 7 must reduce input 1 by 21088311 MAD to be efficient. To improve its performance, the company must analyze the practices of companies 2 , and 27 that are identified as its peers of reference. To be a peer (or benchmark), an organization must have $100 \%$ pure efficiency. The lambda weight associated with each peer corresponds to the relative importance of that peer within the group of identified peers. Ideally, company 7 should analyze the best practices of a virtual company formed by $38.1 \%$ of company 2 , and $61.9 \%$ of company 27 . Since such a virtual company does not exist, our company should focus its best practice analysis on the company with the highest lambda value (i.e. company 27 ).

There is a remarkable difference between industries in terms of efficiency, with the highest value in technical efficiency VRS of 1 for the manufacture of food products (beverages, canned fish) and the lowest value of 0.01 for industrial sausage products.

\section{Conclusion}

Technology transfer is the main driving force for the industrial development of Morocco's emerging processing industries.

In this study, the contribution of technology transfer to the processing industries in the Souss Massa region was studied. Based on data from 48 firms, the DEA model is constructed to evaluate the efficiency of technology transfer. Empirical analyses are conducted to examine the efficiency of technology transfer.

This paper analyzes efficiency in the processing industries of the Souss-Massa region. The reason for the difference between industries is the different levels of mastery of the new technologies transferred.

In the survey of innovative enterprises in the region, it was found that in investment in innovation and technology transfer, the investment of funds contributes to the production of other innovative technologies that were not taken into account at the beginning of the technological investment, which shows that the production of innovation is always stimulated by the funds.

In addition to R\&D personnel, the personnel using new technologies also undergo a positive externality of technical progress, i.e. new technical skills.

The study revealed that there is also a creative potential that has been developed among R\&D and engineering staff. The results can help not only to improve the results of technological innovation, but also to make optimal use of input factors.

Inefficient technical investment in certain processing industries can be transformed into efficient investment by analysing peers or benchmarks.

This study could also serve as a support to study the efficiency of technology transfer within innovative enterprise groups or clusters.

\section{References}

1. Agrawal, A. (2001). Common property, forest management and the Indian Himalaya. Contributions to Indian Sociology, 35(2), 181-212.

2. Feichtinger, G., Lambertini, L., Leitmann, G., \& Wrzaczek, S. (2016). R\&D for green technologies in a dynamic oligopoly: Schumpeter, Arrow and inverted-U's. European Journal of Operational Research, 249(3), 1131-1138.

3. Halkos, G.E., \& Salamouris, D.S. (2004). Efficiency measurement of the Greek commercial banks with the use of financial ratios: a data envelopment analysis approach. Management accounting research, $15(2), 201-224$. 
4. Hamdani, M. \& Bendou, A., 2019. Technology Transfer Analysis in Industrial Ecosystems: Case of Souss-Massa Processing Industries. Journal of Advanced Research in Dynamical and Control Systems, 1(11), 1072-1087.

5. Huguenin, J.M. (2013). Data Envelopment Analysis. Dans: Multi-Criteria Decision Analysis. Chichester, UK: John Wiley \& Sons Ltd, 235-274.

6. Jolly, D.R. (2013). How to evaluate your technologies ? The Expansion Management Review, 149(2), 122-130.

7. Shepherd, R.W. (2016). Theory of cost and production functions. s.1.:Princeton University Pres.

8. Vinig, T., \& Lips, D. (2015). Measuring the performance of university technology transfer using meta data approach: the case of Dutch universities. The Journal of Technology Transfer, 40(6), 1034-1049.

9. Wunsch-Vincent, S. (2018). WIPO Global Innovation Index 2018. s.1.:s.n. 